\title{
O GERENCIAMENTO DE DANOS AMBIENTAIS NA SOCIEDADE DE RISCO E A EMERGÊNCIA DE UM DIREITO AMBIENTAL TRANSNACIONAL PRIVADO
}

\author{
THE MANAGEMENT OF ENVIRONMENTAL DAMAGE IN RISK SOCIETY AND THE \\ EMERGENCE OF A PRIVATE TRANSNATIONAL ENVIRONMENTAL LAW
}

\author{
Bruno Dantas \\ Pós-Doutor (UERJ) \\ FGV - RJ, UERJ, UNINOVE \\ dantasbruno@outlook.com
}

Caio Victor Ribeiro dos Santos

Pós-graduado em Direito Processual Civil - IDP

Instituto Brasiliense de Direito Público (IDP/Brasília-DF)

caiovrds.ac@gmail.com

\begin{abstract}
Resumo: O dano ambiental é típico da sociedade de risco: invisível, global e de potencial catastrófico. Por apresentar variáveis bem mais complexas que o ilícito civil comum, exige um tratamento específico e diferenciado da ordem jurídica. Conduzido pelo método dedutivo, em pesquisa bibliográfica que se serviu de obras nacionais e estrangeiras, este artigo objetiva discorrer sobre a natureza do dano ambiental, buscando lançar luz sobre pontos essenciais e fornecer subsídios para seu correto tratamento pelo ordenamento jurídico. Após discorrer sobre a natureza do dano ambiental e a tensão de correntes que divergem quanto ao seu enfrentamento, o artigo demonstra a emergência de um direito ambiental transnacional, pautado na criação de obrigações ambientais pela via dos contratos, como uma nova luz no tratamento e prevenção da ocorrência de danos ambientais.
\end{abstract}

Palavras-chave: Danos ambientais. Sociedade do risco. Direito transnacional ambiental

Abstract: Environmental damage is typical of a risky society: its invisible, global and potentially catastrophic. As this kind of damage presents much more complex features than common torts, it requires specific and differentiated treatment of the legal order. Adopting the deductive method and the procedure of bibliographic review, this article has the purpose of discussing the nature of environmental damage, seeking to shed light on essential points and provide for its correct treatment by the legal system. After exposing the nature of environmental damage as well as conflicting opinions on how to deal with it, the article points out the emergence of a transnational environmental law based on the creation of environmental obligations through private contracts as a new light to the management and prevention of environmental damages.

Key-words: Environmental damage. Risk society. Transnational environmental law.

\section{Para citar este artigo}

ABNT NBR 6023:2018

DANTAS, Bruno; SANTOS, Caio Victor Ribeiro dos. O gerenciamento de danos ambientais na sociedade de risco e a emergência de um direito ambiental transnacional privado. Prisma Jurídico, São Paulo, v. 19, n. 2, p. 195-209, jul./dez. 2020.

http://doi.org/10.5585/prismaj.v19n2.16952. 


\section{Introdução}

O Século XXI, marcado, entre outros fenômenos, pela globalização e transição da sociedade industrial para a sociedade do risco, trouxe consigo a peculiar característica de exigir, dos mais diversos ordenamentos jurídicos, uma necessidade de repensar seus regimes de responsabilidade civil, público ou privados, para lidar com os danos.

Produto natural da vida em sociedade, os danos não podem ser extintos, senão evitados. A tomada de consciência de que se vive, atualmente, uma sociedade do risco, requer que sejam os danos visualizados não por uma perspectiva individual (lie the loss where it falls), mas coletiva, solidária, de comunicação, visto que os bens e serviços de que decorrem são, em regra, usufruídos e pela sociedade global como um todo.

Os danos ambientais não fogem a essa realidade. Pelo contrário, são característicos de uma sociedade de risco global: invisíveis, não obedecem a fronteiras entre nações ou divisas entre estados, e além disso possuem potencial catastrófico.

O recente vazamento de petróleo que se espalhou pelo Nordeste brasileiro, devido às suas múltiplas variáveis, reaqueceu o debate em torno da natureza do dano ambiental, trazendo à luz a suspeita de que seu gerenciamento exige mecanismos mais flexíveis. ${ }^{1}$

Fenômenos, ou melhor, tragédias como essa, levantam questões do tipo: seria o dano ambiental um problema unicamente jurídico? Como deve ser feita a quantificação do prejuízo sofrido? Quem é o juiz competente, se o dano, via de regra, não é estático? Quem tem direito a propor a ação judicial, as pessoas afetadas ou todos os interessados? (VALENZUELARENDÓN, 2015, p. 127 - 140) Como deve se dar a responsabilização quando o dano atinge múltiplos países, ou quando ignora-se o seu responsável, a exemplo de muitos derramamentos de petróleo ao mar?

Partindo da hipótese de que os danos ambientais, como se apresentam ao mundo hoje, exigem a articulação do pensamento para métodos mais flexíveis de prevenção, o que se pretende, neste singelo ensaio, é discorrer acerca do gerenciamento dos danos ambientais no mundo globalizado, buscando lançar luz sobre sua natureza e pontos essenciais, a fim de subsidiar o correto endereçamento das questões feitas acima.

\footnotetext{
${ }^{1}$ Não sem razão o direito ambiental tem-se revelado campo fértil para a temática das decisões estruturais. Nesse sentido, assevera Sérgio Cruz Arenhart: "Muitas decisões em ação coletiva ambiental têm imposto a obrigação de sujeitar qualquer modificação na área afetada à prévia manifestação (ou orientação) do órgão ambiental competente, ou ainda a de condicionar a prática de certos atos com repercussão ambiental à prévia autorização do órgão de fiscalização ambiental. É natural que as várias facetas existentes nos litígios ambientais e a necessidade de proteção simultânea de diversos interesses façam com que aqui as decisões estruturais sejam ainda mais necessárias”. (ARENHART, 2013, p. 20)
} 
Para estruturar o artigo, que é conduzido pelo método indutivo, servimo-nos de pesquisa bibliográfica e documental, tanto nacional quanto estrangeira. Nas ilustrações pertinentes, optou-se por utilizar exemplos de casos envolvendo o derramamento de óleo ao mar, considerando a atualidade do tema pelos acontecimentos recentes no Brasil.

Dessa maneira, a fim de expor o que nos propomos, dividimos o trabalho em três partes: a primeira, dedicada a explicitar as características do dano ambiental na sociedade de risco; a segunda, destinada a verificar como a tensão entre duas correntes ideológicas impacta diretamente nas múltiplas formas de enfrentamento do dano ambiental; e a terceira, por fim, em que demonstramos a emergência de um direito ambiental transnacional privado como uma nova luz para lidar com esse tipo de dano.

\section{0 dano ambiental na "sociedade do risco"}

Os danos são subprodutos da vida em sociedade e dela indissociáveis. O que distingue os sistemas jurídicos, neste ponto, não é propriamente a natureza do dano, sobretudo em um mundo globalizado em que a fruição de serviços e bens é cada vez mais compartilhada e homogênea, e sim a forma como gerenciam os danos que produzem. Anderson Schreiber anota que "a cada sistema jurídico compete decidir o que fazer com diversos danos produzidos, implicando a própria ausência de decisão, neste caso, em uma decisão em si, que corresponde a 'deixar o dano onde cair' (the loss lies where it falls)."

A transição da sociedade industrial para aquilo que Ulrich Beck (1992) descreveu como a "sociedade do risco" é um evento importante no que diz respeito aos danos ambientais. Para Beck, a transição da sociedade industrial para a sociedade pós-industrial do risco traz uma série de novas características paras as relações e estruturas sociais.

A sociedade industrial, segmentada em classes, tem sua estrutura regida fundamentalmente por uma lógica de distribuição de riquezas, de modo que nela a distribuição dos riscos seguiria o padrão da classe dominante: enquanto a riqueza se concentraria no topo, os riscos, em regra, seriam acumulados e divididos na base. Nessa acepção, os riscos podem ser qualificados como hierárquicos, pessoais e calculáveis (BECK, 1992, p. 35).

Vem dessa sociedade a noção capitalista-moderna e também tradicional do regime de responsabilidade civil, que reserva aos danos um remédio individualista (que contrapõe um autor a um réu, desconsiderando a dimensão coletiva do ato ilícito), restritivo (em que o ônus de comprovar os pressupostos necessários recai pesadamente sobre o acionador do remédio), 
a ex-post facto (acionável apenas após a ocorrência do dano) e pecuniário (que termina com a entrega de soma em dinheiro) (SCHREIBER, 2008, p. 744).

A natureza restritiva desse remédio é uma característica fortemente delatora do compartilhamento dos riscos apenas na base da estrutura social. Conforme anota Schreiber, as "dificuldades de demonstração da culpa atendiam [na sociedade industrial], plenamente, ao propósito liberal de ampliar ao máximo o espaço da autonomia privada, sem criar desnecessários desestímulos ao exercício da vontade individual. " O intuito era justamente dificultar o dever de reparar da classe responsável por prover serviços e circular bens, de modo que o dano fosse menos um problema de quem o produzisse e mais de quem o sofresse (the loss lies where it falls), obrigando a vítima de um dano a superar as, inúmeras vezes, intransponíveis barreiras da demonstração da culpa do ofensor e do nexo de causalidade entre sua conduta e o dano. A inversão do ônus da prova é uma conquista apenas recente, e valiosa, para o gerenciamento dos danos em sociedade.

Por outro lado, a "sociedade do risco", na acepção de Ulrich Beck (1992, p. 29), é fundamentada na lógica de distribuição dos riscos, tendo em vista o seu próprio desenvolvimento tecnológico. Esses novos riscos tendem a ser invisíveis (às descrições científicas e aos sentidos humanos), globais (não se limitam às barreiras de um território em específico) e de potencial catastrófico (consequências irreversíveis ou de longa duração).

Assim, enquanto a sociedade industrial apresenta como características centrais a estratificação social e a distribuição de riqueza, respondendo a danos concretos ou perceptíveis, a "sociedade do risco", ou sociedade pós-industrial, é caracterizada pela distribuição dos riscos, cabendo-lhe gerenciar, sobretudo, riscos invisíveis e globais.

Dentro desse contexto pós-industrial é que se inserem os riscos ecológicos, caracterizados por sua invisibilidade, transnacionalidade e potencial catastrófico. Como destacam Ravanello e Lunelli (2020, p. 141) “os riscos não possuem limitação espacial e temporal, os perigos são cumulativos e seu potencial destrutivo é muito grande, podendo ocasionar catástrofes de extensão global." Essas características, que tornam o dano ambiental, sua consequência, extremamente impactante, são os motores que incitam o desenvolvimento de um regime de responsabilidade cada vez mais aderente às vicissitudes do mundo globalizado.

Com a multiplicação massiva dos danos após o desenvolvimento do capitalismo industrial, cresce a tendência de se retirar dos ombros das vítimas a histórica carga probatória que lhes havia legado o direito moderno (SCHREIBER, 2008, p. 747). O regime tradicional de responsabilidade é ex-post facto e aplica sanções após a demonstração do nexo causal, 
porém, o gerenciamento dos riscos em uma sociedade pós-industrial requer decisões que operem de outra forma, visto que tais riscos são, muitas das vezes, completamente ignorados pelo sistema jurídico e pela ciência, às vezes anônimos, além de ser difícil em muitas ocasiões comprovar o nexo causal entre eles, a conduta e o dano ambiental.

Dessa forma, a fim de endereçar devidamente os riscos e danos ambientais, o conceito tradicional de responsabilidade civil teria de ser reinterpretado em diversos aspectos, sobretudo o nexo de causalidade e a imputação da responsabilidade, de modo a compatibilizálos com a realidade de que os danos constituem um problema coletivo. Não se trata propriamente de uma socialização dos danos, mas de uma socialização ou "comunicação dos riscos", na acepção de Luhmann (2005), visto que a ampliação dos danos acidentais são consequências de atividades socialmente úteis e aproveitadas por todos. ${ }^{2}$

A própria conceituação do dano ambiental, a depender do ponto de vista adotado, gera interpretações diversas sobre o seu regime de responsabilidade, como veremos.

\section{O dano ambiental entre o "antropocentrismo" e o "ecocentrismo"}

Há quase dois séculos, Heine alertava os franceses para não subestimarem o poder das ideias: conceitos filosóficos desenvolvidos na quietude do gabinete de um professor poderiam destruir uma civilização (BERLIN, 1981, p. 227). O poeta alemão se referia à filosofia de Kant, que teria colocado fim no deísmo alemão, e à Rousseau, mentor intelectual de Robespierre, que levou suas ideias para a Revolução Francesa e terminou sujando-as de sangue. O mesmo se diga, ao revés, do poder das ideias para a construção de uma civilização, a exemplo do mito de Rômulo e Remo para e expansão civilizatória romana ou do ideal salvacionista protestante no sucesso inicial do capitalismo norte-americano (WEBER, 2004).

Essa realidade é marcadamente presente no campo do direito ambiental, onde a discussão dos direitos ambientais perpassa uma tensão entre duas correntes ideológicas cuja divisão vai desaguar, em última instância, em políticas públicas. Enquanto há quem se contente com os conceitos atuais de sustentabilidade, para outros a marcha do direito ambiental não se sustentará em passo progressivo se não lograr romper, concomitantemente,

\footnotetext{
${ }^{2}$ Nessa linha, destaca Anderson Schreiber (2008, p. 747): “A ampliação dos danos acidentais, anônimos, como produtos inevitáveis de atividades socialmente úteis, chamaram atenção para a necessidade de $\mathrm{s}$ enxergar a responsabilidade civil não apenas como um mecanismo de atribuição do ônus indenizatório a quem deve reparar um dano, mas a quem pode repará-lo. Vive-se um momento de erosão dos filtros da reparação, no qual a prova da culpa e a prova do nexo causal vêm perdendo, gradativamente, seu papel de contenção do ressarcimento."
} 
com certos aspectos de mais de dois milênios de pensamento ocidental sobre o meio ambiente, que posiciona o ser humano no centro da proteção. ${ }^{3}$

A discussão ética no âmbito do direito ambiental surgiu, naturalmente, como uma resposta à mentalidade predatória e insustentável da natureza que, pelo menos no Brasil, já vem sendo combatida há algumas décadas, com todos os instrumentos da Política Nacional do Meio Ambiente. Nesse contexto é que se inserem as duas tendências sobreditas: de um lado, o “antropocentrismo ecológico" e, de outro, o "ecocentrismo".

Essencialmente, ambas as correntes divergem mais em grau do que em tipo quanto à seguinte questão: merece o meio ambiente proteção em razão do valor que apresenta para a vida humana, ou em razão de si mesmo, pelo valor intrínseco que possui? A questão não é abstrata ou de pouca utilidade prática; na verdade, tem repercussão jurídica direta nos meios de tutela do meio ambiente, visto que dela decorre uma distinção entre danos ambientais de natureza diversos que atraem, por consequência, regimes diferentes de responsabilização, além de influenciar a própria feitura de políticas públicas.

Destaca José Roque Junges (2001, p. 36) que o "antropocentrismo" "admite a existência de deveres humanos, ao menos indiretos, em relação à natureza ou de uma responsabilidade dos humanos pelos recursos naturais diante das gerações futuras. " Trata, essa corrente, de limitar a intervenção na natureza para a preservação de seus recursos para os próprios seres humanos. É antropocêntrica porquanto os critérios para as restrições são os interesses, as necessidades ou preferências humanas, e não tanto a natureza em si.

É o que se acha, por exemplo, na própria definição tradicional de "sustentabilidade", adotada pela Comissão Mundial sobre o Meio Ambiente e Desenvolvimento (Bruntland Comission), e que se pode encontrar na doutrina, que prescreve: "Desenvolvimento sustentável é o desenvolvimento que atende às necessidades do presente sem comprometer a capacidade das gerações futuras de atender às suas próprias necessidades. "4 Isto é: as necessidades em torno do qual giram o conceito são as necessidades humanas. Por essa definição, continuar-se-ia a permitir que fosse reduzida em boa monta a diversidade

\footnotetext{
${ }^{3}$ Nesse sentido, assevera Peter Singer (2010, p. 309-310): "Embora a atitude contemporânea face aos animais seja suficientemente benévola - numa base muito seletiva - para permitir a introdução de melhorias nas condições de vida dos animais sem questionar a nossa atitude básica, estas melhorias estarão sempre em perigo se não conseguirmos alterar a posição subjacente que sanciona a exploração brutal dos não humanos para fins humanos. Só poderemos contribuir para a abolição desta exploração se conseguirmos romper radicalmente com mais de dois mil anos de pensamento ocidental relativo aos animais."

4 Ver documento Report of the World Commission on Environment and Development. Disponível em: http://www.un-documents.net/ocf-02.htm\#I. Acesso em: 19 jan. 2020.
} 
ecológica, condicionando-a, no entanto, à possibilidade de que as gerações futuras sejam capazes de conviver com essa redução. ${ }^{5}$

São igualmente manifestações dessa concepção ambiental expressões como o "bemestar da população", "sadia qualidade de vida", não raro adotadas pela legislação brasileira ambiental quando da invocação das razões para as medidas de tutela ambiental.

O "ecocentrismo", por sua vez, também denominado "biocentrismo ecológico", considera a natureza sujeita de direitos. Adota por ponto de partida a ideia de que todo sujeito de vida merece consideração moral, não podendo o ser humano se antepor e definir, pelo seu ponto de vista, o valor que aquele possuiria. Anota Junges (2001, p. 40), que "quem possui esse ponto de vista é o depositário de valor inerente e titular de direitos inalienáveis, não podendo sofrer alterações e interferências no curso da sua vida."

Aqui, leva-se em consideração uma série de critérios para se definir o que seria um sujeito de vida com capacidade de direito, que varia tanto quanto os autores que se debruçam sobre o tema: identidade psicofísica, capacidade de desejos e atuar com objetivo (REGAN, 1983), a capacidade de sentir dor e prazer, de ter consciência (SINGER, 2010, p. 201), a organização biológica (TAYLOR, 1986), entre outros. Grosso modo, trata, o ecocentrismo, de rejeitar a ética ecológica kantiana, para defender que não apenas o homem, mas também a natureza como um todo é um "fim em si mesmo", digna de tutela em razão do valor intrínseco que teria. ${ }^{6}$

É exemplo dessa visão ecocêntrica o fenômeno da personalização jurídica dos animais, que faz uma releitura do direito das coisas, atenuando o rigor do jus utendi, jus fruendi e jus abutendi e rompe, assim, com a influência do personalismo ético, que tornou-se a principal diretriz do Direito Civil desde as codificações do século XIX e colocou os animais, enquanto coisas, à mercê do livre sabor dos interesses humanos (AZEVEDO, 2008, p. 115 - 126).

Nota-se, portanto, que a depender do tipo de interesses humanos tem-se duas éticas sutilmente distintas: uma ética de conservação, e outra de preservação. Enquanto a ética de conservação, preocupada com as necessidades materiais dos humanos, está interessada em

\footnotetext{
5 Nesse sentido, Kortetmaki (2013, p.35): "This definition would still allow us to decrease environmental diversity a great deal, as far as human generations are able to live with that decrease."

${ }^{6}$ Kant possuía um entendimento peculiar acerca da ética animal e é tido como um dos aliados da concepção antrocêntrica de meio ambiente. Apesar da ideia explorada em suas obras de que o "o homem é um fim em si mesmo", não tratou o autor de estender essa concepção para a natureza - o que é feito atualmente pelas correntes ecocentristas, que concebem a natureza como um fim em si mesmo - e propugnava a restrição à crueldade com os animais sob o argumento de seu potencial nocivo de incentivo à crueldade com humanos, e não por qualquer valor intrínseco que possuísse. De acordo com Sara Fernandes Gonçalves (2015, p. 9), “Já a visão de Kant, no século 18, considerava que animais eram sencientes, mas que, no entanto, nós não tínhamos obrigação moral direta para com eles: condutas de crueldade para com os animais são incorretas, mas apenas em razão de induzirem à crueldade com humanos, ou ferir os interesses humanos. "
} 
conservar os recursos naturais tendo em vista sua limitação e também por pertencerem às gerações futuras, a ética de preservação pretende preservar a natureza para o seu próprio respeito, para ao crescimento humano e interiorização espiritual (JUNGES, 2001, p. 36).

Essa estrutura teórica repercute sobre a natureza do dano ambiental. O meio ambiente é um sistema composto de múltiplos elementos, sendo um deles o ser humano. E o dano ambiental lato sensu, embora seja de difícil conceituação e apresente diversas definições para denominá-lo ${ }^{7}$, pode ser dividido em duas espécies em função da sua conexão com esse elemento humano: dano indireto e dano direto aos seres humanos.

Evidentemente, ambos os tipos de danos ferem o ser humano enquanto membro de um sistema holístico. Os graus de violação, a depender do enfoque, é que são diferentes. Considera-se direto o dano ambiental quando ele atinge o patrimônio ou a saúde das pessoas, sendo também conhecido, por parte da doutrina, como dano individual ambiental (PINHO, 2010, p. 139 - 140); e indireto, quando atinge qualquer outro elemento da natureza que não o humano, também chamado de dano ambiental per se ou dano ecológico puro (LEITE, 2003).

Em um caso, como o recente no Brasil, de derramamento de petróleo ao mar, pode-se verificar a existência do dano ambiental indireto (puro) na contaminação da água e areia e no comprometimento do ecossistema marinho causado pelas espessas borras de óleo, podendo-se dele destacar o dano ambiental direto (individual), que se acha nas consequências à saúde causadas pelo contato humano com o material, que podem ir desde náuseas, vômitos, gastroenterite, ao favorecimento de desenvolvimento de câncer. ${ }^{8}$

Não se trata, a distinção, de mero preciosismo teórico: na verdade, a falta de uma diferenciação precisa, por muito tempo, fez com que o direito ambiental carecesse de instrumentos aderentes à realidade do dano. Em boa parte dos países latino americanos, por exemplo, os danos indiretos e diretos ao meio ambiente ainda são tratados da mesma maneira, apesar do esforço da doutrina que, apenas mais recentemente, vem alterando essa realidade. No Brasil, a Lei de Crimes Ambientais (Lei 9.605/1998) se refere em diversos dispositivos ao

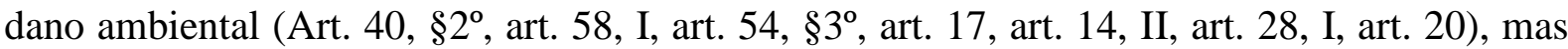
não entabula legalmente a diferenciação entre os tipos de danos ambientais. Pesquisa

\footnotetext{
${ }^{7}$ Carvalho (2013, p. 102), inclusive, anota que a abstração do conceito de dano ambiental é algo positivo: "A existência de previsão expressa do conceito de dano ambiental favorece uma construção dinâmica de seu sentido na interação entre a doutrina e os tribunais, atendendo à necessária ponderação dos interesses em jogo e à garantia da qualidade de vida assegurada constitucionalmente. $\mathrm{O}$ dano ambiental detém um conceito aberto, dependendo da avaliação do caso concreto pelo intérprete para a sua configuração, em face da dimensão multifacetária que engendra seu diagnóstico."

8 As pesquisas acerca das consequências à saúde causadas pelo contato humano com o petróleo bruto foram conduzidas após a catástrofe de Deep Water Horizon, ocorrida em 2010 (KWOK et al, 2017).
} 
desenvolvida por José Juan Gonzáles, professor mexicano, mostrou que essa é realidade do Chile, Brasil, Costa Rica, Cuba e Nicarágua. ${ }^{9}$

Sem distinção precisa, a consequência resultante foi, e por vezes ainda o é, a inapropriada aplicação do direito privado para a resolução de questões envolvendo o dano ambiental, que apresenta variáveis bem mais complexas do que o ilícito civil comum.

Neste ponto, um dos casos mais marcantes a nível mundial envolvendo dano ambiental causado por derramamento de óleo foi o caso Chevron, petrólifica norte-americana que por trinta anos debateu nas cortes de vários países os limites de sua responsabilidade pela contaminação à floresta amazônica do Equador durante os anos de 1964 a 1992, causada pela Texaco (empresa adquirida pela Chevron). Um dos pontos mais polêmicos da discussão estava em saber se o acordo realizado à época pela Texaco perante o governo equatoriano para a limpeza da área - na qual foram empregados 40 milhões de dólares - absolveria ou não a sucessora de qualquer responsabilidade futura. ${ }^{10}$

O caso é emblemático, entre outros aspectos, por colocar em tensão a aplicação do direito privado e o direito ambiental público à espécie, bem como por questionar os parâmetros usados na mensuração dos danos ecológicos. Quando da época da realização do acordo, o Equador carecia de uma legislação regulatória apropriada à matéria, de modo que a quantificação do valor fixada em acordo para a reparação foi ditada sobremaneira pela ótica do direito civil, e por isso, naturalmente, questionada mais tarde.

É possível que essa mesma discussão venha a ser, eventualmente, suscitada quanto aos limites preclusivos dos TACs (termos de ajustamento de conduta) em matéria ambiental: até onde se pode invocar a segurança do negócio jurídico perfeito, ou a própria segurança jurídica do empreendedor, como legítimo argumento para uma limitação estanque da responsabilidade por danos ambientais, sobretudo quando o responsável vier a cumprir efetivamente as cláusulas do acordo pactuadas à época do evento danoso?

Sobre a responsabilidade em relação ao dano ambiental, registra Paulo de Bessa Antunes (2020, p. 256):

\footnotetext{
${ }^{9}$ Ver documento La responsabilidadad por el daño ambiental em la América Latina, de autoria de José Juan Gonzáles Márquez. Disponível em: http://centro.paot.org.mx/documentos/pnud/Dano_ambiental.pdf. Acesso em: 20 jan. 2020.

${ }^{10}$ Nesse sentido, anota Robert V. Percival (2010): “Chevron's defense is that everything it did in Ecuador was legal and that it spent $\$ 40$ million on environmental cleanup and was released from further liability by the government of Ecuador in 1992 when Texaco left the country. The plaintiffs claim that this settlement with a too-compliant government does not absolve Texaco of responsibility for the harm their activities caused to the individual plaintiffs in the lawsuit. While the litigation over environmental devastation caused by oil production in Ecuador has been underway for nearly two decades, the basic legal question at the heart of the controversy is remarkably simple: Should governments be able to insulate private companies from liability for acts that foreseeably cause significant harm to others?"
} 


\begin{abstract}
"O dano ambiental é de difícil reparação. Daí que o papel da responsabilidade civil, especialmente quando se trata de mera indenização (não importa seu valor), é sempre insuficiente. Por mais custosa que seja a reparação, jamais se reconstituirá a integridade ambiental ou a qualidade do meio que for afetado. Por isso, indenizações e compensações serão sempre mais simbólicas do que reais, se comparadas ao valor intrínseco da biodiversidade, do equilíbrio ecológico ou da qualidade ambiental. A prevenção nesta matéria - aliás, como em quase todos os aspectos da sociedade industrial - é a melhor, quando não a única solução.
\end{abstract}

A quantificação de danos, portanto, em matéria ambiental, não deve levar em consideração tão somente seu impacto ao patrimônio ou saúde das vítimas - o que se faria sob uma perspectiva antropocêntrica e obsoleta do assunto -, mas tendo em conta, igualmente, seu impacto direto e isolado ao meio ambiente, sob uma perspectiva ecocêntrica, tendo em vista que sua perda, enquanto sujeito autônomo de direitos, embora simbolicamente avaliada a título de reparação, é sempre maior do que se pode mensurar.

Deve-se, com isso, ter claro que a conceituação do dano ambiental lato sensu em danos indiretos e diretos aos seres humanos, considerando as peculiaridades de cada um, é de suma relevância para a matéria, visto que conduz a regimes diversos de responsabilização: enquanto os danos diretos atraem o regime privado, os danos indiretos atraem o regime público. Essa distinção revela que devemos enxergá-la da mesma maneira que Wittgenstein (1994) visualizava as palavras em geral: elas podem não ter fronteiras precisas, tampouco ser definidas exaustivamente, mas ainda são úteis à discussão.

\title{
4 Direito ambiental transnacional privado: a emergência de um modelo contratual para a prevenção de danos ambientais
}

Os danos pertencem à sociedade. Em um mundo globalizado, e cujos sistemas jurídicos têm passado a conceber também o meio ambiente como sujeito de direitos, os danos ambientais não podem ser vistos como um problema tão só daquele que o sofre diretamente, mas de todos. Rejeita-se a ideia de "deixar o dano onde ele cair".

Notáveis são os esforços da comunidade internacional em torno do desenvolvimento de um direito ambiental global pela via diplomática, da negociação de tratados multilaterais entre os países. Isso se deve ao "efeito bumerang", que, segundo Gomes e Simioni (2020, p. 158-159) consiste na ideia de que os riscos na sociedade moderna "retornam e alcançam quem os produziu ou lucrou com eles, e portanto, dada a natureza transnacional dos riscos, faz-se necessária a implementação de direitos por meio de documentos internacionais". Apesar 
disso, o que se nota é que baixo tem sido o progresso que essa via tem produzido para a efetiva prevenção de ameaças ambientais. ${ }^{11}$

Dentro desse quadro de prevenção, registra Mariana Heck, em extensa pesquisa sobre o tema, que a dificuldade de lidar com os danos ambientais, no que concerne o derramamento de óleo ao mar, parece não estar na legislação, cuja fartura é inquestionável, mas na forma como os atores, privados ou públicos, têm feito sua aplicação:

o problema parece não estar nas convenções, e sim no modo como elas são aplicadas: não parece estar na estrutura, no conteúdo ou na qualidade das disposições jurídicas, mas, talvez, na inabilidade em implementá-las ou na falta de estímulo para seu cumprimento. Assim, a OMI não tem priorizado a modificação dos seus instrumentos de trabalho (convenções, resoluções, guidelines, códigos de conduta), e sim o método de adoção deles, os meios de implementação e o controle de sua aplicação. (HECK, 2012, p. 212).

Nessa esteira, à margem do tradicional direito internacional, novas esferas e formas de elaboração de normas vocacionadas a regular a proteção do meio ambiente têm surgido, tornando o Estado apenas mais um ator entre outros capazes de endereçar questões ambientais com repercussão internacional (PEREIRA, 2016, p. 19). Esse movimento ocorre pela via da normatização e contratualização privada, numa espécie de private goals for public gains, sobre a qual escrevemos em outra oportunidade envolvendo as class actions, que não só aumenta a qualidade da regulação, como cria uma rede global e voluntária de proteção.

Vem do setor privado os maiores riscos para a natureza e, não sem razão, na "era da sustentabilidade" espera-se das empresas um comportamento sustentável (PEREIRA, 2016, p. 19), sob pena, inclusive, de responsabilização pela via do direito público ambiental. Entretanto, se este cria um incentivo exterior à conformidade com as normas de proteção ambiental, a submissão a elas pela via dos contratos privados cria um incentivo interno aos envolvidos.

Estímulos econômico-privados podem ser mais efetivos para a tutela ambiental que os estímulos comuns esperados da legislação pública, sobretudo quando a condição imposta goza de um caráter extraterritorial. À título de exemplo, empresas e países não participantes da União Europeia, se quiserem ter acesso ao mercado europeu, precisam se adequar às diretivas daquela acerca da proteção ambiental, como no caso de comercialização de produtos químicos, organismos geneticamente modificados, utilização de energia proveniente de fontes renováveis, entre outras exigências (PEREIRA, 2016, p. 22).

\footnotetext{
${ }^{11}$ Exemplo disso foi a Conferência de Copenhagen em 2009, cujo acordo acerca das mudanças climáticas não foi aprovado à unanimidade pelos países participantes e tampouco goza de força vinculativa (PERCIVAL, 2010, p. 21).
} 
Como assevera Priscila Pereira (2016, p. 24), “o interesse geral de proteção do meio ambiente e os interesses particulares das empresas podem coexistir por meio do instrumento contratual. "À parte do direito público, os contratos podem constituir uma fonte autônoma e voluntária de obrigações ambientais, regulando, por exemplo, as formas de conservação e de exploração das florestas, a forma de negociação dos créditos de redução das emissões de gases de efeito estufa negociados no mercado de carbono, o nível da qualidade sustentável de biocombustíveis, a submissão a regras específicas de tratados internacionais que versem a emissão de gases e mudanças climáticas, entre outros.

As possibilidades são múltiplas. Nesse contexto, fornecedores exercem relevante função em prol da extraterritorialidade dessas normas privadas, tendo em vista a posição que ostentam na cadeia comercial. É o caso das condições de compra impostas em contratos internacionais celebrados pela empresa Royal Dutch Shell, as quais se referem, a título de exemplo, à obrigação de respeitar condições de trabalho impostas pelas Convenções da OIT (Organização Internacional do Trabalho) ou à obrigação de preservar a biodiversidade em algumas regiões úmidas, conforme Convenção de Ramsar (PEREIRA, 2016, p. 24).

No que toca o gerenciamento dos riscos pelos danos ambientais, o ponto alto desse modelo é que a normatização pública e privada internacional, uma vez internalizada na esfera do direito privado pelos termos contratuais, adquire força vinculante, afastando-se as dificuldades inerentes à voluntariedade no cumprimento das normas internacionais.

Exemplificando, empresas petrolíferas poderiam, na celebração de contratos com transportadoras de petróleo, exigir submissão ao Oil Pollution Act (OPA 90) dos Estados Unidos, legislação interna norte-americana que impôs requisitos de casco duplo para os navios-petroleiros, faixas de idade, além de prazo de retirada para os petroleiros de casco simples, mas que só vincula os navios que navegam nas águas daquele país. ${ }^{12}$

O gerenciamento dos riscos em uma sociedade pós-industrial requer decisões que fujam à mera lógica tradicional de produção legislativa. A fartura de convenções e outras normas versando sobre a poluição por óleo é prova de que a comunidade internacional tem grande interesse no tema, e sua proliferação nos últimos anos, que esse interesse ainda não diminuiu. No entanto, pouco progresso têm elas produzido. Se o que se pretende é a

\footnotetext{
12 Releva destacar, nesse exemplo, que a partir de 2005 os petroleiros de casco simples foram banidos das águas norte-americanas e, em decorrência disso, começaram a operar em outras regiões do mundo, inclusive no Brasil, onde a legislação ainda os tolera. Isso aumenta o risco de poluição do mar nos países que seguem tão somente os requisitos impostos pelas convenções internacionais (a exemplo da Convenção Internacional para a Prevenção da Poluição por Navios e Convenção Internacional sobre o direito no mar), as quais foram julgadas insuficientes, pelos Estados Unidos, para a efetiva proteção contra a poluição, após o desastre de Exxon Valdez em 1989. Daí por que terem editado o Oil Pollution Act, com requisitos mais rigorosos para os navios petroleiros que navegam em suas águas, elevando o nível de sua proteção ambiental.
} 
construção de uma rede transnacional de prevenção a tais tipos de dano, é preciso que a comunicação dos riscos seja introduzida e entremeada em toda cadeia comercial, tendo em conta que, muitas vezes, obrigações contratuais são mais fortes que obrigações legais.

Daí por que o relevante papel das multinacionais e dos fornecedores na implementação de uma efetiva política de sustentabilidade e redução de riscos. Não basta se intitular sustentável: é preciso garantir que seus parceiros comerciais também o sejam.

\section{Considerações finais}

A transição de uma sociedade industrial para a sociedade do risco deve ser acompanhada de uma consequente modificação de seus regimes de gerenciamento de riscos: em um mundo onde a maior parte dos riscos de danos, ou a mais letal dela, é de danos invisíveis, como os danos ambientais, o foco deve recair não sobre regimes ex post de responsabilidade, mas sobre uma rede ex ante de prevenção difusa.

Se se concebe o meio ambiente por um viés ecocentrista, toda responsabilização após o evento danoso é resultado de uma perda já irreparável e, ainda que se atribua algum valor ao dano causado, ele há de ser sempre simbólico e incapaz de representar a verdadeira perda que a natureza terá de suportar, às vezes, por milhares de anos.

Quanto aos vazamentos de óleo, o problema parece não estar nas convenções e normas jurídicas já existentes sobre o tema - cuja abundância é inquestionável e, no entanto, ainda insuficiente para evitar os milhares de vazamentos documentados anualmente, sobretudo vindo de navios. O problema reside na aplicação dessas normas. Por isso, cresce a importância do que se vem denominando de direito ambiental transnacional privado: um conjunto de regras, práticas e processos desenvolvidos pelo setor privado, e implementado pela via contratual, em que se estabelece cláusulas de proteção ambiental como condições para a negociação com parceiros comerciais.

$\mathrm{Na}$ era da sustentabilidade, espera-se das empresas que se comportem de forma sustentável, e fazê-lo é um dever que não pode se encerrar de forma isolada em um ator apenas, mas deve ser transferido para toda a cadeia comercial: não basta se dizer sustentável, é preciso garantir que aqueles com quem se faz negócios também o sejam.

\section{Referências}

ANDRADE, Priscilla Pereira de. A emergência do direito transnacional ambiental. Revista de Direito Internacional, v. 13, n. 3, 2016, p. 19-28. Disponível em: 
https://www.publicacoesacademicas.uniceub.br/rdi/article/view/4491. Acesso em: 21 jan. 2020.

ANTUNES, Paulo de Bessa. Direito ambiental. 21. ed. São Paulo: Editora Atlas, 2020.

ARENHART, Sérgio Cruz. Decisões estruturais no direito processual civil brasileiro. Revista de Processo, v. 225, 2013.

AZEVEDO, Antonio Junqueira. Crítica ao personalismo ético da Constituição da República e do Código Civil: em favor de uma ética biocêntrica. Revista da Faculdade de Direito da Univerisdade de São Paulo, v. 103. p. 115-126, jan./dez. 2008,

BERLIN, Isaiah. Quatro ensaios sobre a liberdade. Trad. Wamberto Hudson Ferreira. Brasília, Editora Universidade de Brasília, 1981.

CARVALHO, Délton Winter de. Dano Ambiental Futuro: a responsabilização civil pelo risco ambiental. 2. ed. Porto Alegre: Livraria do Advogado, 2013.

DANTAS, Bruno; RIBEIRO, Caio Victor. Dos entusiastas aos "estrangeiros" da jurisdição coletiva nos EUA: como incentivos errados transformaram as class actions em mercadoria. Interesse Público - IP, Belo Horizonte, ano 21, n. 114, p. 36-46, mar./abr. 2019.

GONÇALVES, Sara Fernandes. Utilitarismo, deontologia kantiana e animais: análise e avaliação críticas. Dissertação (Mestrado em Filosofia) - Universidade Federal de Uberlândia. Uberlândia, 2015.

GOMES, Renata Nascimento; SIMIONI, Rafael Lazzarotto. Direito ambiental e gestão de riscos: o princípio da precaução na orientação da estrutura e sistemática dos pressupostos para concessão de medidas processuais de urgência. Revista Direito Ambiental e Sociedade, v. 10, n. 1, p. 158-159, jan./abr. 2020. Disponível em:

http://www.ucs.br/etc/revistas/index.php/direitoambiental/article/view/8600. Acesso em: 23 jun. 2020.

HECK, Mariana. A ação normativa da organização marítima internacional e seus instrumentos em face da poluição marítima por óleo causada por navios. Revista de Direito Internacional, v. 9, n. 3. p. 193-218, 2012. Disponível em: https://www.publicacoesacademicas.uniceub.br/rdi/article/view/2051/1952. Acesso em: 21 jan. 2020.

JUNGES, José Roque. Ética ecológica: antropocentrismo ou biocentrismo? Pespec. Teol., Belo Horizonte, n. 89, v. 33, 2001.

KORTETMAKI, T. Anthropocentrism versus Ecocentrism Revisited: Theoretical Confusions and Practical Conclusions. SATS: Northern European Journal of Philosophy, v. 14, n. 1, p. 21-37, 2013. Disponível em:

https://jyx.jyu.fi/bitstream/handle/123456789/42918/anthropocentrismvsecocentrismunpublis hed.pdf? sequence=1. Acesso em: 20 jan. 2020.

KWOK, Richard K et al. The Gulf Study: A Prospective Study of Persons Involved in the Deepwater Horizon Oil Spill Response and Clean-Up. Enviromental Heal Perspectives. v. 
125, n. 4, 2017. Disponível em: https://ehp.niehs.nih.gov/doi/pdf/10.1289/EHP715. Acesso em: 20 jan. 2020.

LEITE, J. R. M. Dano Ambiental: do individual ao coletivo extrapatrimonial. 4. ed. São Paulo: LTr, 2003.

LUHMANN, Niklas. Risk: a Sociological Theory. Edison: Aldine Transaction, 2005.

PERCIVAL, Robert. V. Liability for Global Environmental Harm and the Evolving Relationship between Public and Private Law. 25 Md. J. int'L. 37. Disponível em: https://digitalcommons.law.umaryland.edu/cgi/viewcontent.cgi?article=2021\&context=fac_pu bs. Acesso em: 21 jan. 2020

PINHO, Hortênsia Comes. Prevenção e Reparação de Danos Ambientais: as medidas de reposição natural, compensatórias e preventivas e a indenização pecuniária. Rio de Janeiro: GZ Verde, 2010.

RAVANELLO, Tamires; LUNELLI, Carlos Alberto. Princípio da precaução, irreparabilidade dos danos ambientais e tutela do meio ambiente. Prisma Jurídico, São Paulo, v. 19, n. 1, p. 138-152, jan./jun. 2020. Disponível em: http://doi.org/10.5585/prismaj.v19n1.10469. Acesso em 23 jun. 2020.

REGAN, Tom. The case for Animal Rights. Los Angeles: The regents of the University of California, 1983.

SCHREIBER, Anderson. Responsabilidade civil como política pública. In: FACHIN, Edson; TEPEDINO, Gustavo (org.). O direito e o tempo: embates jurídicos e utopias contemporâneas - Estudos em homenagem ao Professor Ricardo Pereira Lira. - Rio de Janeiro: Renovar, 2008.

SINGER, Peter. Libertação Animal. São Paulo: WMF Martins Fontes, 2010.

TAYLOR, Paul W. Respect for Nature: a Theory of Environmental Ethics. Princeton: Princeton University Press, 1986.

ULRICH, Beck. Risk Society: Towards a New Modernity, London, Sage, 1992.

VALENZUELA-RENDÓN, Angelina Isabel. The damage to the Environment: a view from law. Athens Journal of Law, v. 1, Issue 2, p. 127 - 140, 2015.

WEBER, Max. A ética protestante e o "espírito" do capitalismo. Trad. José Marcos Mariani de Macedo. São Paulo: Companhia das Letras, 2004.

WITTGENSTEIN, L. Tractatus logico-philosophicus. São Paulo: Edusp, 1994. 